Lexis Vol. XLIV (1) 2020: 205-244

\title{
Julio Cortázar y la formación de palabras*
}

\author{
Luis González García \\ Universidade da Coruña (UDC), Grupo Hispania
}

\section{RESUMEN}

En este trabajo se analiza el proceso de creación de palabras en la producción literaria de Julio Cortázar. Tras un apartado introductorio en el que nos centramos en la preocupación de Cortázar por la regeneración de la novela hispanoamericana, uno de cuyos pilares es la renovación del léxico literario, el resto del artículo se dedica al análisis en detalle de los procedimientos utilizados en la creación de nuevas palabras. En primer lugar, estudiaremos las creaciones de carácter jitanjafórico. En segundo lugar, abordaremos la utilización de mecanismos regulares que la lengua ofrece para la renovación del léxico (derivación, composición, entrecruzamiento, palíndromos y anagramas, etc.).

Palabras clave: Formación de palabras, morfología léxica, neologismos, Cortázar

\footnotetext{
Este trabajo se ha realizado en el seno del Grupo de Investigación HISPANIA (G000208) de la Universidad de A Coruña, que ha sido reconocido como Grupo de Potencial Crecimiento y ha recibido una ayuda de consolidación de la Xunta de Galicia (ref. ED431B 2019/28).
} 
Cortázar’s Word Formation

\section{Abstract}

In this paper we analyze the process of word formation in the literary production of Julio Cortázar. After an introductory section focused on his aim of regeneration of the Latin American novel, one of whose pillars is the renewal of the literary lexicon, the rest of the article is devoted to a detailed analysis of the procedures used by Cortázar in the creation of new words. Firstly, we study creations of a jabberwocky nature (jitanjáforas). Afterward, we attend to the use of the regular mechanisms that language offers for this purpose (derivation, composition, blending, palindromes and anagrams, etc.).

Keywords: Word formation, lexical morphology, Spanish neologisms, Cortázar

\section{Introducción}

En este trabajo nos proponemos analizar, principalmente desde un punto de vista lingüístico, la relación establecida entre un escritor y el material básico de su producción, las palabras. Mientras que sobre la figura de Cortázar los acercamientos de índole literaria son inabarcables, los de carácter lingüístico, por el contrario, prácticamente no existen (Mañu Iragui 1974; Castro 2016). Sin embargo, si los lingüistas tenemos por objeto de estudio importante, entre otras unidades, la palabra, sería esperable que investigaciones de esta naturaleza sobre uno de los genios de creación y manipulación de las palabras en español se prodigaran más.

En estas páginas pretendemos, pues, analizar los procedimientos utilizados por Cortázar para crear nuevas palabras dentro de su plan de renovación del léxico literario en la novela hispanoamericana.

El cuerpo de nuestro estudio se divide en tres apartados principales: en el primero ( $\$ 3$ ) examinaremos la especial relación que desde niño se produjo entre Cortázar y la entidad palabra, relación que se cimentaría posteriormente en su labor profesional de traductor y, en su faceta literaria, en su intento prolongado de crear una lengua literaria no literaria, es decir, renovada. En las otras dos 
secciones nos centraremos en el análisis concreto de la creación léxica: en la segunda $(\mathbb{S} 4)$ nos ocuparemos de aquellas construcciones neológicas carentes de motivación (jitanjáforas), como las incluidas en el glíglico y otras lenguas características de algunos de

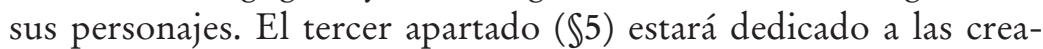
ciones neológicas realizadas de acuerdo con las reglas de formación de palabras del castellano.

\section{Marco teórico y corpus manejado}

Los estudios sobre neología o creación léxica cuentan con una larga tradición en la investigación gramatical del español, en cuyos inicios podemos situar la aportación pionera de Alemany y Bolufer (1920). Con todo, es a partir del último cuarto del siglo XX cuando se produce un espectacular desarrollo de este tipo de publicaciones. Es imposible mencionar en este lugar la larga serie de trabajos centrados en esta especialidad morfológica: obras de carácter general, estudios sobre facetas particulares (composición, derivación, parasíntesis...) o su aplicación a algún tipo de texto (la neología en la prensa, en la publicidad, en el lenguaje científico, etc.). Es tal la cantidad de aportaciones sobre este aspecto del lenguaje que no escasean los inventarios bibliográficos. En Serrano Dolader (2012), se mencionan diez repertorios, junto con una selección de trabajos clásicos en la materia (lo que nos evita una mención detallada), que todavía podría completarse con alguna contribución reciente (Casado Velarde 2015).

Resultado de esta larga labor investigadora, que abarca desde la gramática tradicional hasta el descriptivismo estructuralista europeo o el generativismo, más allá de las lógicas discrepancias de escuela, entre los estudios hay un cierto consenso acerca de conceptos como el de morfema, lexema, raíz, tema, base, o procesos como la flexión, la derivación (la afijación, prefijación, sufijación, infijación, interfijación), la composición, la sustracción o acortamiento, junto con procesos complejos como la siglación y la acronimia, el entrecruzamiento, etc. Remitimos a Pena (1991; 1999) o Casado (2015) para una acertada descripción de todos estos procedimientos. 
En el párrafo anterior hemos hecho alusión a una importante faceta dentro de los estudios neológicos: los enfocados hacia el análisis de algún tipo especial de texto. Entre estos trabajos debería ocupar un lugar destacado el relativo al análisis de la lengua literaria, dadas las especiales cualidades reconocidas en los autores literarios (recordemos que autor-AUCTOR- se relaciona con autoridad -AUCTORITAS-).

Y, en efecto, podemos mencionar algunos trabajos orientados hacia la creación de neologismos en la lengua literaria, elaborados desde una perspectiva general (Romero Gualda 1980, González Calvo 2003) o centrados en algún autor que destaque en la utilización de este procedimiento: Gabriela Mistral (Oroz 1967), César Vallejo (Meo Zilio 1968), Juan Ramón Jiménez (González Calvo 1981), Camilo José Cela (Soldevila Durante 1990), Vicente Aleixandre (López Martínez 1992), Juan Goytisolo (Martín Camacho 1994; 1995), Francisco Nieva (Serrano Dolader 1997), Mario Benedetti (Herrero 2001), Manuel Pacheco (Pulido Mendoza 2001), Gloria Fuertes (García-Page 2009), César Vallejo (García-Page 2012), Juan Gelman (García Ávila 2013; Heredia 2014), Laureano Albán (Campos López 2017), etc.

Entre estos estudios hallamos en falta uno dedicado a la figura de Julio Cortázar, pues este autor, como intentaremos demostrar a lo largo de las páginas que siguen, mostró una preocupación por la renovación del léxico -tanto en el plano teórico como en la práctica literaria- para la que es difícil encontrar parangón en nuestra tradición literaria moderna.

Ha sido el afán de contribuir a paliar esta carencia lo que nos ha movido a elaborar este trabajo, para cuya confección hemos tenido en cuenta algunos de los textos de crítica literaria compuestos por el autor francoargentino así como el grueso de sus obras narrativas: cuentos, novelas y misceláneas ${ }^{1}$.

A lo largo del texto se utilizan las siguientes abreviaturas para identificar las obras de Cortázar más citadas: $[\mathrm{C}]=$ Cuentos completos, $[\mathrm{M}]=62$. Modelo para armar, $[\mathrm{L}]$ Libro de Manuel, $[\mathrm{R}]=$ Rayuela . Las ediciones manejadas figuran en la bibliografía final. 


\section{La renovación del léxico. La destrucción de la palabra}

Las obras que constituyen nuestro corpus muestran una permanente preocupación en Cortázar por la creación léxica. La ruptura que propone en el plano literario se continúa en el lingüístico como resultado de una profunda reflexión de tipo metalingüístico y metaliterario. En toda su producción, está presente el anhelo y la necesidad de encontrar una nueva literatura, de romper con una literatura psicologicista que le decepciona y con la lengua que le sirve de instrumento comunicativo ("una lengua hecha de frases [...] preacuñadas para transmitir ideas archipodridas” R345), que estarían representadas, aunque no exclusivamente, por la literatura realista que escarnece a través de Lo probibido de Galdós, en el capítulo 34 de Rayuela ${ }^{2}$. Comparable a Joyce, Cortázar intenta crear una antinovela que suponga el fin de la novela (de la novela anquilosada se entiende $)^{3}$. Ahora bien, si la novela debe morir para renacer, también habrá que acabar con las palabras (las palabras predecibles, tópicas) y sustituirlas por otras nuevas. La palabra es un obstáculo más que hay que salvar en esta ímproba tarea de renovación.

La paradoja radica en que para acabar con las palabras debemos acudir a las palabras, puesto que intentar prescindir de ellas no parece factible: "Sin palabras llegar a la palabra (qué lejos, qué improbable)” (R216).

\footnotetext{
2 En este capítulo, Oliveira se burla mentalmente del léxico que va leyendo en la novela de Galdós que la Maga tiene en su mesilla (el texto galdosiano va marcado en cursiva): “lo que en verdad era poco lisonjero para un [...] hombre que... Lisonjero, desde quién sabe cuándo $[\ldots]$ no oía esa palabra, cómo se nos empobrece el lenguaje a los [...] criollos, de chico yo tenía presentes muchas más palabras [...] que ahora, leía esas mismas novelas, me adueñaba de un $[\ldots]$ inmenso vocabulario perfectamente inútil por lo demás, $[\ldots]$ pulcro y distinguidísimo, eso sí” (R345).

3 La visión de Cortázar sobre este asunto queda reflejada en sus escritos de crítica literaria, especialmente en Teoría del túnel (1947) y Situación de la novela (1950), recogidos en Cortázar (2006).
} 


\subsection{La fascinación por las palabras y el diccionario}

Un conocido libro resultado de un diálogo prolongado entre Cortázar y Omar Prego lleva por título significativo La fascinación de las palabras (Prego 1985). En esta obra, Cortázar confiesa que esa especial relación con las palabras comenzó ya en su primera infancia cuando percibió de manera nítida la primordial dicotomía entre el signo y su referente, distinción demasiado precoz (los psicopedagogos sitúan el pensamiento abstracto en una fase muy posterior del desarrollo infantil) que estuvo a punto de causarle problemas psicológicos, como él mismo señala:

JC: [...] Un niño aprende que eso se llama silla y entonces después pide una silla o busca una silla, pero para él la palabra "silla" ya no tiene sentido separada de la cosa. Se ha vuelto un valor simplemente funcional de utilización.

Curiosamente mis primeros recuerdos son de diferenciación. O sea, una especie de sospecha de que si yo no exploraba la realidad en su aspecto de lenguaje, en su aspecto semántico, la realidad no era completa para mí, no era satisfactoria. E incluso -esto ya un poco después, a los ocho o nueve años- entré en una etapa que podría haber sido peligrosa y desembocado en la locura: las palabras empezaban a valer tanto o más que las cosas mismas (Prego 1985: 24-25).

Esa conciencia de la palabra como entidad autónoma será una constante en la producción literaria de Cortázar. Mientras que para el hablante usual el amor puede suscitar ciertas emociones, en Cortázar es la palabra amor la que las suscita ("Pero el amor, esa palabra...” R592). En la conversación antes apuntada (Prego 1985: 25), nuestro autor señala que en esa fase de su infancia las palabras le producían múltiples sensaciones: "las palabras que me gustaban, las que no me gustaban, las que tenían un cierto dibujo, un cierto color". Muchos años después, en Rayuela todavía se suceden expresiones como las siguientes:

En un tiempo Morelli había pensado un libro que se quedó en notas sueltas. La que mejor lo resumía es ésta: «Psicología, palabra con aire de vieja [...]» (R523). 
Hasta hace unos veinte años había la gran respuesta: la Poesía, ñata, la Poesía. Te tapaban la boca con la gran palabra (R614).

...a Horacio la palabra traición, la palabra engaño lo ponían furioso (R285).

...cuando llegaste estaba en pleno trance shamánico, a punto de tirarme por el agujero para terminar de una vez con las conjeturas, esa palabra esbelta (R477).

...sapiens es otra vieja, vieja palabra, de esas que hay que lavar a fondo antes de pretender usarla con algún sentido (R524).

En estas circunstancias, con una sensibilidad como la que apuntamos, no es de extrañar que el futuro escritor sustituyese los juegos propios de su edad por actividades centradas en los libros: la escritura de cuentos y poemas, las largas horas dedicadas a la lectura que tanto preocupaban a su madre e, incluso, le provocaron terrores nocturnos por un tiempo (Marchamalo 2011: 38).

Entre estas actividades figuraba una que no le abandonaría nunca: el trabajo con el diccionario. Evidentemente, su relación con el diccionario fue evolucionando conforme el niño ávido de conocer palabras nuevas se fue convirtiendo en traductor y en el creador que nos deslumbraría en el arte de la manipulación del lenguaje $\mathrm{e}^{4}$. Otra de sus aficiones de infancia fueron las definiciones del diccionario. Pasaba horas sentado con un Pequeño Larousse que le habían regalado, en el que buscaba palabras y significados: goleta, porrón, tifus... (Marchamalo 2011: 39).

Como pronto veremos, esta admiración que suponemos en el niño sentado delante del diccionario en busca de palabras y definiciones se convirtió años más tarde en desdén ante un objeto despreciable. Cuando la búsqueda de una nueva realidad literaria hizo que el caudal almacenado en su seno se considerase insuficiente o falto de representatividad, el diccionario se convierte en

\footnotetext{
4 La huella de la presencia del diccionario en su producción literaria es palpable, como se aprecia en las siguientes citas: "Intimidad, qué palabra [...]. Pero qué otra palabra podría intimar (en primera acepción) la piel misma del conocimiento, la razón epitelial de que Talita, Manolo y yo seamos amigos” (R555), "Los perfumes, los himnos órficos, las algalias en primera y en segunda acepción...” (R723).
} 
cementerio de palabras y así, el cementerio, pasa a denominarse en Rayuela. Este nombre, sin embargo, no le resta protagonismo: en todas sus obras y especialmente en esta última, las alusiones al cementerio como fuente de artificios léxicos son constantes. La preocupación metalingüística originada en su niñez se manifiesta ahora en prácticas y juegos que llevan a cabo profusamente sus personajes (los juegos del cementerio, las preguntas-balanza).

\subsection{Los juegos en el cementerio, las preguntas-balanza}

Las reglas de los "juegos con el cementerio" o "en el cementerio" no están explícitamente descritas en Rayuela, pero la obra ofrece suficientes datos (capítulos 40 y 41) como para que el lector pueda deducirlas. Se trata de buscar una palabra en el diccionario y elaborar un texto con cierto sentido usando otros vocablos presentes en la misma página de ese diccionario:

Como les encantaba jugar con las palabras, inventaron en esos días los juegos en el cementerio, abriendo por ejemplo el de Julio Casares en la página 558 y jugando con la hallulla, el hámago, el halieto, el haloque, el hamez, el harambel, el harbullista, el harca y la harija (R385).

Fue a buscar el diccionario de la Real Academia Española, en cuya tapa la palabra Real había sido encarnizadamente destruida a golpes de gillete, lo abrió al azar y preparó para Manú el siguiente juego en el cementerio.

«Hartos del cliente y de sus cleonasmos, le sacaron el clíbano y el clípeo y le hicieron tragar una clica. Luego le aplicaron un clistel clínico en la cloaca, aunque clocaba por tan clivoso ascenso de agua mezclada con clinopodio, revolviendo los clisos como clerizón clorótico.»

— Joder — dijo admirativamente Oliveira. Pensó que también joder podía servir como punto de arranque, pero lo decepcionó descubrir que no figuraba en el cementerio; en cambio en el jonuco estaban jonjobando dos jobs, ansiosos por joparse; lo malo era que el jorbín los había jomado jitándolos como jocós apestados. 
«Es realmente la necrópolis», pensó. «No entiendo cómo a esta porquería le dura la encuadernación.» (R393-394)

En realidad, para el juego en el cementerio no basta con crear un texto más o menos ingenioso: la participación de una segunda persona permite insertar palabras inventadas que, evidentemente, el interlocutor debe identificar: puede tratarse de palabras existentes levemente modificadas o verdaderas creaciones léxicas. En la cita anterior son creación de Cortázar cleonasmos, probablemente deturpación de pleonasmos o errata por clenasmo (Mañu 1974: 94), jonjobando (la forma recogida en el diccionario es jonjabar) y jorbin (forma inexistente). Este tipo de creaciones ex nibilo nos pone en relación con el glíglico, que más abajo comentaremos ${ }^{6}$.

El juego de las preguntas-balanza es más complejo, si bien González Dueñas (2013) nos ofrece una plausible justificación de su funcionamiento. El texto de Rayuela nos proporciona diversos ejemplos, todos ejecutados en el mismo escenario surrealista poco propicio, en un principio, para el juego (Talita montada a caballo de un puente de tablones tendido entre las ventanas colindantes del apartamento que comparte con Traveler y del de Oliveira, atrapada a mitad de camino ${ }^{7}$ :

Oliveira encendió un cigarrillo. Los tablones se habían equilibrado otra vez. Aspiró satisfecho el humo.

\footnotetext{
5 En esta última cita, el diccionario manejado es el académico Diccionario Manual e ilustrado de la Lengua Española, de 1950, en concreto las páginas 382 (cléptómanoclorbídrico, ca) y 385 (jipi-jornada). Por la voz jonuco sabemos que Cortázar no usa el diccionario académico por excelencia, el Diccionario de la Lengua Española (DLE), cuya decimoctava edición había aparecido en 1956. Jonuco (“Méj. Chiribitil, cuarto obscuro”) figura en todas las ediciones de este diccionario manual $(1927,1950,1984,1989)$ pero no fue incluido en el diccionario "usual” o "común” de la Academia, el DLE, hasta 2001 (“Méx. Espacio que hay debajo de la escalera de una casa”).

6 Los juegos de diccionario son sumamente frecuentes, sobre todo como actividad lúdica escolar. En España, en lo que nosotros sabemos, es relativamente usual la variante en la que varios participantes deben adivinar el significado de una palabra extraída del diccionario por otro jugador: ganan puntos quienes aciertan la definición verdadera pero también aquellos otros que elaboran una definición suficientemente convincente como para que sea votada por otros jugadores.

7 En Prego (1985: 109) reconoce que presenció una escena semejante en Buenos Aires.
} 
-Mirá, hasta que vuelva ese idiota de Manú con el sombrero, lo que podemos hacer es jugar a las preguntas-balanza.

—Dale — dijo Talita—. Justamente ayer preparé unas cuantas, para que sepas.

-Muy bien. Yo empiezo y cada uno hace una pregunta-balanza. La operación que consiste en depositar sobre un cuerpo sólido una capa de metal disuelto en un líquido, valiéndose de corrientes eléctricas, ¿no es una embarcación antigua, de vela latina, de unas cien toneladas de porte?

-Sí que es —dijo Talita, echándose el pelo hacia atrás-. Andar de aquí para allá, vagar, desviar el golpe de un arma, perfumar con algalia, y ajustar el pago del diezmo de los frutos en verde, ¿no equivale a cualquiera de los jugos vegetales destinados a la alimentación, como vino, aceite, etc.?

- [...] Es espléndido. Pero escuchá esto: Reverdecer, verdear el campo, enredarse el pelo, la lana, enzarzarse en una riña o contienda, envenenar el agua con verbasco u otra sustancia análoga para atontar a los peces y pescarlos, ¿no es el desenlace del poema dramático, especialmente cuando es doloroso?

—Qué lindo —dijo Talita, entusiasmada-. Es lindísimo, Horacio. Vos realmente le sacás el jugo al cementerio (R407).

Citando estas muestras, señala González Dueñas (2013) que la esencia del juego consiste en detectar relaciones metafóricas, es decir, relaciones de semejanza entre un dominio fuente (término figurado) y un dominio meta (término real). Sobre esta base, el objetivo de las preguntas-balanza radica en desafiar al interlocutor para que adivine la relación existente entre ese término real $(\mathrm{A}) \mathrm{y}$ el término figurado $(B)$ : ¿A “no es” $B$ ? ¿A “no equivale” a $B$ ? $\dot{A}$ “no se parece mucho a” $\mathrm{B}$ ? El reto es grande, porque la relación se establece entre campos semánticos aparentemente inconexos entre sí. Además, tan importante o más que adivinar las palabras concretas que entran en la ecuación es la tarea de hallar esas secretas relaciones, que se escapan muchas veces a la lógica:

Primero, Oliveira ha abierto al azar el diccionario y su vista ha caído en "galvanoplastia"; pero no le interesa la palabra definida 
sino los modos de la definición ("arte de sobreponer a cualquier cuerpo sólido una capa de metal disuelto en un líquido, valiéndose de corrientes eléctricas, procedimiento con que suelen prepararse moldes para vaciados y para la estampación estereotípica”), de la que su intuición poética toma lo esencial. Luego establece la pregunta “¿no es...?” y sus ojos saltan un corto trecho para caer en "galizabra” ("embarcación de aparejo latino de unas cien toneladas de porte”). El equilibrio es completo y no resta sino observar la imagen metafórica, la conexión, que está más allá de las palabras que la desencadenaron.

Puede sin duda ponerse en palabras el hallazgo y contemplar los resultados de los campos semánticos fusionados; basta ver cómo de un lado la palabra "líquido" establece un diálogo inmediato con "embarcación”, cuyos términos asociados son "mar", "agua"; así brota otra línea de identidad: las corrientes eléctricas y las corrientes del mar (González Dueñas 2013: 47-48).

Todos estos juegos nos llevan por un camino muchas veces señalado a propósito de esta obra en concreto (y de la producción de Cortázar en general): la concepción de Rayuela como juego, como un rompecabezas, en el que el lector es colaborador necesario, participante activo involucrado en el desciframiento de la obra ${ }^{8}$ : debe reconocer, entre todas esas palabras exóticas y eufónicas seleccionadas para el juego, cuáles son creaciones, cuáles realmente existen y cuáles son sus relaciones, al igual que hacen La Maga, Talita, Traveler y Oliveira. Desde esta perspectiva, otro de los recursos léxicos con los que Cortázar juega con el lenguaje, el glíglico, cobra, creemos, un nuevo sentido.

\section{La creación léxica desmotivada. Del glíglico a la fortrán}

Como es bien sabido, el glíglico es una lengua inventada por la Maga, con la que se comunica con Oliveira. En principio, el glíglico

\footnotetext{
8 Por oposición al "lector pasivo" de la novela realista: "Ya en su primera novela, Los premios, se burla Cortázar del lector pasivo, cómodo, apegado a la rutina: el que está interesado solamente por «qué-va-a-pasar-al-final»; al que le gusta que le lleven, cogido de la nariz, y le den la novela ya digerida, como una papilla” (Amorós [1963] 1984: 23).
} 
es una lengua secreta (como otras lenguas jergales creadas para no ser entendidas por las personas ajenas al grupo) que utilizan los dos personajes en contextos amorosos. Como otras lenguas secretas, el glíglico utiliza la gramática (morfología, sintaxis, fonología) de la lengua base. La clave está en la sustitución parcial del léxico. En uno de los capítulos prescindibles de Rayuela, el 68, Cortázar nos ofrece el ejemplo más extenso de esta lengua':

Apenas él le amalaba el noema, a ella se le agolpaba el clémiso y caían en hidromurias, en salvajes ambonios, en sustalos exasperantes. Cada vez que él procuraba relamar las incopelusas, se enredaba en un grimado quejumbroso y tenía que envulsionarse de cara al nóvalo, sintiendo cómo poco a poco las arnillas se espejunaban, se iban apeltronando, reduplimiendo, hasta quedar tendido como el trimalciato de ergomanina al que se le han dejado caer unas fílulas de cariaconcia. Y sin embargo era apenas el principio, porque en un momento dado ella se tordulaba los hurgalios, consintiendo en que él aproximara suavemente sus orfelunios. Apenas se entreplumaban, algo como un ulucordio los encrestoriaba, los extrayuxtaba

\footnotetext{
9 Disponible en la propia voz de Cortázar en https://www.youtube.com/ watch?v=qevRdIoXCsg (Fecha de consulta: 21 de julio de 2017). La audición muestra la importancia de la sonoridad, de la eufonía, en este lenguaje.

El glígico cuenta con antecedentes conocidos, como es el caso del poema Jabberwocky incluido por Lewis Carrol en Alicia a través del espejo (1871). En la literatura en español debemos considerar también los antecedentes de César Vallejo (Trilce, de 1922) y Vicente Huidobro en Altazor (1931) y especialmente en la farsa para guiñol En la luna (1934), préglígico en palabras de Lagmanovich (1997: 270): “Señores y conciudadanos: La Patria en solemifados momentos me elijusna para directar sus destídalos y salvantiscar sus princimientos y legicipios sacropanzos. No me ofuspantan los bochingarios que parlantrigan y especusafian con el hambrurio de los hambrípedos. No me ofispantan los revoltarios, los infiternos descontinfechos que amotibomban el poputracio" (cit. en Pradenas 2006: 280).

Si comparamos el preglíglico de Huidobro y el glíglico de Cortázar podemos observar que se trata de lenguas literarias en las que como único recurso diferenciador se produce la sustitución léxica de adjetivos, sustantivos y verbos. El uso de ambas lenguas se limita a situaciones muy determinadas (Lagmanovich 1997: 275), lo que facilita la interpretación de los textos: un discurso político en un caso, una escena amorosa en el otro. La principal diferencia entre ambos lenguajes estriba en que en Huidobro se procede a una deformación grotesca de lexemas reconocibles (solemifados 'solemnes', destídalos 'destinos', salvantiscar 'salvar', sacropanzos 'sacrosantos', etc.), en tanto que en Cortázar los procedimientos son más variados, como se verá.
} 
y paramovía, de pronto era el clinón, la esterfurosa convulcante de las mátricas, la jadehollante embocapluvia del orgumio, los esproemios del merpasmo en una sobrehumítica agopausa. ¡Evohé! ¡Evohé! Volposados en la cresta del murelio, se sentían balparamar, perlinos y márulos. Temblaba el troc, se vencían las marioplumas, y todo se resolviraba en un profundo pínice, en niolamas de argutendidas gasas, en carinias casi crueles que los ordopenaban hasta el límite de las gunfias (R533).

Pero si nuestra interpretación es adecuada (aunque sea solo parcialmente) y el glíglico forma parte del juego, el lector colaborador se encuentra como en el caso del juego del cementerio ante la necesidad de determinar cuáles de estas palabras son inventadas y cuáles existen (¿encontraremos arnilla y espejunar en Casares o en el Diccionario de la Lengua Española (DLE)?, ¿cuáles son palabras del cementerio y cuáles creaciones, pues en el glíglico se combinan ambas?). Es por tanto la sublimación del juego del cementerio ${ }^{10}$.

En otras muchas obras echa mano Cortázar de este tipo de creación léxica desmotivada total o parcialmente. Especialmente interesantes por la relevancia en el tono de la obra nos parecen sus novelas 62. Modelo para armar (1968) y Libro de Manuel (1973). En medio, en un microrrelato ("La inmiscusión terrupta") incluido en otro collage suyo, Último round (1969), utiliza también este procedimiento. Algunos de los pasajes más conocidos de estas obras nos muestran cómo el autor logra efectos diferentes:

10 Este es el comienzo del capítulo 144 de Rayuela: "Los perfumes, los himnos órficos, las algalias en primera y en segunda acepción... Aquí olés a sardónica. Aquí a crisoprasio" (R723). Todas son palabras recogidas en el Diccionario Manual de 1950. Es evidente que el resultado pretendido intenta emular el léxico inventado propio del glíglico. La ironía es clara, pero si tenemos en cuenta el capítulo 20, el juego todavía parece complicarse más, pues da a entender que hay una manera adecuada de jugar, de crear esas palabras (no basta la creación totalmente arbitraria): "El glíglico lo inventé yo — dijo resentida la Maga. Vos soltás cualquier cosa y te lucís, pero no es el verdadero glíglico” (R221222). Si es que existen (y Cortázar no juega con nosotros también en este punto), buscar las claves del verdadero glíglico podría ser un ejercicio apasionante, comparable solo al dedicado por Ferdinand de Saussure en los últimos años de vida al desciframiento de las claves ocultas en el verso saturnio y los anagramas (Rodríguez Ferrándiz 1997). 


\section{LA INMISCUSIÓN TERRUPTA}

Como no le melga nada que la contradigan, la señora Fifa se acerca a la Tota y ahí nomás le flamenca la cara de un rotundo mofo. Pero la Tota no es inane y de vuelta le arremulga tal acario en pleno tripolio que se lo ladea hasta el copo.

-¡Asquerosa! -brama la señora Fifa, tratando de sonsonarse el ayelmado tripolio que ademenos es de satén rosa. Revoleando una mazoca más bien prolapsa, contracarga a la crimea y consigue marivolarle un suño a la Tota que se desporrona en diagonía y por un momento horadra el raire con sus abroncojantes bocinomias. Por segunda vez se le arrumba un mofo sin merma a flamencarle las mecochas, pero nadie le ha desmunido el encuadre a la Tota sin tener que alanchufarse su contragofia, y así pasa que la señora Fifa contrae una plica de miercolamas a media resma y cuatro peticuras de ésas que no te dan tiempo al vocifugio, y en eso están arremulgándose de ida y de vuelta cuando se ve precivenir al doctor Feta que se inmoluye inclótumo entre las gladiofantas. [...]

Y ahí nomás se recompalmean y fraternulian como si no se hubieran estado polichantando más de cuatro cafotos en plena tetamancia; son así las tofifas y las fitotas, mejor es no terruptarlas porque te desmunen el persiglotio y se quedan tan plopas (Último round II: 110-111).

Para gentes como la señora de Cinamomo es imposible comprender las sesiones de infantilismo que suelen desencadenar esas miradas. Casi siempre es mi paredro el que arranca a partir de Feuille Morte. "Guti guti guti", dice mi paredro. "Ostás ostás fetete”, dice Tell. El más excitado es siempre Polanco. "Pósenos toquetoque sapa", dice Polanco. Como esto suele suceder en una mesa del Cluny, no faltan parroquianos que se sobresalten perceptiblemente. A Marrast le fastidia que la gente sea tan poco plástica, y levanta en seguida la voz. "Tete tete fafa remolino”, dice Marrast con un dedo admonitorio. "Bisbis bisbis", dice Feuille Morte. "Guti guti", dice mi paredro. "Ptac", dice Calac. "Pósenos toconto", dice Polanco. "Ptac", insiste Calac. "Pete sofo", dice Nicole. "Guti guti", dice mi paredro. "Honk honk honk", dice entusiasmado Marrast (M63). 
Si en 62. Modelo para armar las formas así creadas poseen principalmente un valor onomatopéyico, basado especialmente en repeticiones léxicas, en principio carentes de correspondencia con palabras del léxico común, en "La inmiscusión terrupta”, por el contrario, el recurso se asemeja más al glíglico. En ambos casos podemos hablar de innovaciones léxicas de carácter jitanjafórico, aunque de distinta naturaleza según comprobaremos en el apartado siguiente.

\subsection{Creaciones jitanjafóricas}

Entre los múltiples procedimientos utilizados por Cortázar para la creación de un nuevo lenguaje literario que no fuese "literario" figuran las creaciones de tipo jitanfórico. Como es sabido, con este término, tomado de Alfonso Reyes (La experiencia literaria, 1942), se refiere la crítica literaria a aquellas creaciones léxicas fundamentadas en la inmotivación del signo lingüístico, en la arbitrariedad del significante en términos saussureanos.

Como señala Eguren (1987), las jitanjáforas gozan de una larga tradición folklórica y literaria (literatura tradicional, canciones infantiles, poesía negrista...), siempre con una misma finalidad lúdica, si bien será en la literatura de vanguardia o en la originada en ella donde alcance su máxima expresión.

La literatura culta y popular consigue, así, crear significantes nuevos a los que, a diferencia de los propios de las lenguas naturales, se les puede dotar de todas las características y efectos propios de las creaciones artísticas: musicalidad, ritmo, evocación de distintas realidades, etc.

Eguren distingue varios tipos de creaciones jitanjafóricas según se sitúen dentro o fuera de un sistema lingüístico. Nosotros, por nuestra parte, podemos diferenciar, de acuerdo con los ejemplos hasta aquí analizados de Cortázar, tres tipos principales:

1. Aquellas para las cuales no podemos encontrar equivalencia gramatical en castellano (se sitúan fuera de nuestros esquemas fonológico, morfológico y sintáctico). A este tipo pertenecen 
expresiones como "honk honk", “ostás fetete” o "ptac”, recogidas en 62. Modelo para armar ${ }^{11}$.

2. Aquellas construcciones carentes de motivación que se integran en la gramática de una lengua con total naturalidad fonológica, morfológica o sintáctica, insertas en un paradigma nominal o verbal (clémiso, ambonios, sustalos, márulos, alanchufarse) ${ }^{12}$. Se trata de palabras posibles pero no existentes en la lengua, “palabras potenciales” en voz de Eguren (1987: 71). Este tipo de creaciones se fundamenta en el carácter no motivado del signo lingüístico (Saussure). Puesto que no hay motivación en el significante del léxico (con excepción de algunas onomatopeyas y palabras icónicas) no hay otro fundamento más allá de la tradición para que denominemos cadáver (o muerto, difunto, fiambre) a una persona fallecida y no apual, como hace Lonstein (Libro de Manuel).

3. Con todo, en este tipo de jitanjáforas no siempre es total la ausencia de motivación, lo que permite diferenciar un tercer subtipo (jitanjáforas impuras o compuestas), ejemplificado en aquellos casos en cuyo interior se puede rastrear la pervivencia de algunos componentes morfológicos más o menos identificables de la lengua base: prefijos (relamar, entreplumaban, extrayuxtaba), sufijos (esterfurosa, convulcante, arnillas) o elementos léxicos que inciden en el efecto evocativo provocado: bidromurias (bidro-), reduplimiendo (reduplicando), paramovía (mover), jadebollante (jadeante) sobrebumitica (sobrebumano, búmedo), agopausa (pausa), argutendidas (tendidas), carinias casi crueles (caricias), ordopenaban (penar), etc.

11 Otro ejemplo en Rayuela: “Oliveira [...] no pudo resistir a la tentación de sacar un lápiz y escribir la jitanjáfora siguiente: U Nu, / U Tin, / Mya Bu, / Thado Thiri Thudama U E Maung, / Sithu U Cho, / Wunna Kyaw Htin U Khin Zaw, / Wunna Kyaw Htin U Thein Han, / Wunna Kyaw Htin U Myo Min, / Thiri Pyanchi U Thant, / Thado Maba Thray Sithu U Chan Htoon” (R395).

12 Así, por ejemplo, en la discusión mantenida entre los tártaros Polanco y Calac (M5657) se utiliza el verbo buesnar, cuyo significado 'mirar' se adivina; se trata de un verbo de la primera conjugación del que se nos ofrece parte del paradigma regular: buesnando, ha buesnado, buesnan, buesna, buesnó. 
Con frecuencia en Cortázar, todos estos tipos de creaciones jitanjafóricas están asociadas a determinados personajes, personajes excéntricos, extravagantes cuando no absurdos, ridículos o estrafalarios, a los que esta lengua peculiar ayuda a caracterizar ${ }^{13}$. Posiblemente en esta caracterización influya Albert Jarry (18731907), creador de la patafísica, ciencia bien conocida por Cortázar ${ }^{14}$.

En el caso en 62. Modelo para armar se trata de los argentinos (pampeanos) Calac y Polanco, a los que por el motivo aludido califica el narrador con frecuencia de tártaros $^{15}$ :

Desde luego las discusiones no versan en absoluto sobre golondrinas, como puede comprobarlo cualquiera que entienda el idioma de los dos tártaros.

-De todos los que conozco, usted es el más cronco — dice Calac.

-Y usted el más petiforro — dice Polanco-. Me llama cronco a mí, pero se ve que nunca se ha huesnado la cara en un espejo.

-Lo que usted busca es pelearme, don — dice Calac.

Los dos se huesnan con una mulga tremenda. Entonces Polanco saca una tiza y dibuja un zote en el piso [...].

-Yo a usted este trefulgo se lo amafo - dice Polanco que lo huesna pegadísimo-. A mí nadie me tora el zote ni me anda motando de cronco.

- La culpa de lo que pase la tendrá usted que me motó primero - dice Calac.

\footnotetext{
13 Estas formaciones se utilizan también, a modo de muletillas, para identificar a determinados personajes; Feuille Morte (62. Modelo para armar) solo utiliza la expresión "bisbis bisbis" (con la que, por cierto, finaliza la obra) cada vez que interviene; en Libro de Manuel reconocemos a Ludmilla en la interjección blup. Incluso, Manuel, con sus escasos meses, es identificable por su ifctugpi.

14 "Con la Maga hablábamos de patafísica hasta cansarnos, porque a ella también le ocurría [...] caer de continuo en las excepciones” (R127). Como es sabido, la obra más conocida del autor de Gestes et opinions du docteur Faustroll, pataphysicien (1911) es Ubu roi (1897), cuyos personajes, antecedentes del teatro del absurdo, son caracterizados igualmente con neologismos significativos: guidouille, merdre, phynance, etc. (Morales 2014).

15 Denominaciones como esta, tártaro, y otras como bárbaro, bereber, hotentote aluden a la manera de hablar ininteligible de los extranjeros, equiparable a la de los tartamudos. Esta reduplicación se repite en el término gli-gli-co y, por un azar que aprovecha Cortázar, en pampeanos.
} 
—Primero me motó usted —dice Polanco-. Yo entonces lo contramoté como correspondía y usted me tor[ó] el zote y me rebuyó lo de que soy un cronco.

—Yo se lo rebuyí porque usted me huesnó primero (M56-57).

Igualmente interesante es Lonstein, personaje de El libro de Manuel, judío argentino de Córdoba que trabaja en la morgue parisina. No menos estrafalario que los anteriores, Lonstein ha creado, como la Maga, un lenguaje propio al que todos acaban acostumbrándose ${ }^{16}$. Algunas muestras:

-Uno es como esos verdugos clásicos que terminaban neuróticos porque solamente tenían a su hija no menos clásica para contarle los detalles de las tortucomias y las plomochirrías; te das cuenta de que en el bistró de Marthe no voy a andar declinando mi buló, como dicen mis copéns, y eso me condena al silencio aparte de que como soy célibe y castonanista no me queda más exutorio que el soliloquio, aparte del watercuaderno donde de cuando en cuando defepongo uno o dos sorescriptos. Lo malo como te explicaba es que me han doblado el trabajo estos tiempos so pretexto de pagarme cuatro veces más, yo acepté como un prorrumpo incurable y además del insti tengo el hospi (L899).

Por el momento admito que estoy más bien trancado pero no desespero de articulear el totamundo del crefundeo y protuplasmar una nueva estrucultura que comunicaremos inmediatamente a la UNESCO [L1187, la cursiva es nuestra].

Los procedimientos que utiliza Lonstein para crear lo que califica de neofonemas son variados, los propios de las jitanjáforas en general y del glíglico en particular. Con frecuencia, la base se halla en la deformación de lexemas identificables que, ordinariamente, entran en extraños entrecruzamientos, muchos de ellos de difícil

\footnotetext{
16 “A lo mejor es para defenderse, pensó Andrés, que Lonstein habla así valiéndose de un lenguaje que al fin y al cabo todos han terminado por entender, cosa que a veces no parece gustarle demasiado" (L892). "Lo que tengo que reconocer es que lo de las palabras made in Lonstein nunca fueron un juego aunque nadie hubiera podido saber a qué tendían, defensa o agresión, para mí contenían de alguna manera la verdad de Lonstein, eso que era Lonstein” (L892).
} 
interpretación: tortucomias ('torturas'), articulear ('descomponer', 'descifrar', articular+culo), defepongo (defeco+pongo), protuplasmar (proto+plasmar), estrucultura (estructura+cultura), desnupelote integral (desnudo+despelote, L899), dactilopterodear 'dactilografíar' (L1182, derivado de *dactilóptero según el modelo coleóptero, bimenóptero), "se exciforan ('excitan') y se convulrelamen ('convulsionan', 'relamen')" (L963), me incordiumbe (incordia+incumbe, L897), megacordio (L988), plurifundio ('complicación', 'enredo', L1098), etc.

En otros casos, la arbitrariedad —o la dificultad para hallar una motivación léxica - es mayor: apual 'cadáver' (L897), me contorjeo (L905), ficioro (L897), panotear (L898), crefundeo (L1187), sundiales (L899), buló (L899), entre otros muchos ejemplos ${ }^{17}$. Quizás algunos de estos casos pudieran justificarse a partir de la fortrán, código criptográfico que el propio Lonstein nos describe de manera explícita:

-Fortrán es un término significante en el lenguaje simbólico del cálculo científico. En otras palabras, formulación transpuesta da fortrán, y eso no lo inventé yo pero encuentro que es una bonita expresión, y por qué entonces no decir boex por bonita expresión, cosa que economiza fonemas, es decir ecofón, no sé si me seguís, en todo caso ecofón tendría que ser una de las bases del fortrán. Con estos métodos sintetizadores, es decir los mesín, se avanza veloz y económicamente hacia la organización lógica de cualquier programa, o sea el orlopró. En este papelito podés ver el poema envolvente y mnemónico que preparé para retener los neofonemas:

Busca ecofón con un mes'in pero que nunca una fortrán

falte a la cita, si querés

un orlopró de gran coherencia.

¡Boex!

-Parece una de esas jitanjáforas de que hablaba don Alfonso Reyes —aventuró el que te dije con visible fastidio de Lonstein (L1054).

17 Estos dos últimos términos apuntan a otro procedimiento de Cortázar-Lonstein: la utilización de extranjerismos con un significado totalmente nuevo: sundial significa 'reloj de sol' en inglés, bouleau 'abedul' en francés. La adaptación ortográfica de extranjerismos (copéns es otro galicismo, pl. de copain 'compañero, amigo') será tratada con más detalle en el apartado 5 . 
La fortrán se fundamenta, pues, en la formación de siglas (en realidad acrónimos) a partir de las sílabas o fonemas iniciales de las combinaciones léxicas, pero, como hemos visto, no es este el único procedimiento utilizado ${ }^{18}$. En general, el resultado es inteligible cuando parte de lexemas fácilmente reconocibles y, en caso contrario, el contexto facilita la comprensión: “...esta noche Lonstein se supera elocutivamente y dibuja con acento cordobés cosas como apuales y bolaconchados, que por los primeros contextos deduzco que son los ocupantes de las mesas forénsicas” (L897).

Solo en muy contadas ocasiones, Lonstein consiente en traducir o simplificar su elocución: “...yo lo vi nacer en un cantero cerca del río ahí donde les arreglo el jopo a mis apuales. Mis qué, preguntó Heredia. Muertos, dijo Lonstein, está bien, simplificaré para los extranjeros presentes” (L1036).

5. La creación léxica motivada. Las reglas de formación de palabras en Cortázar

La innovación y la renovación que supone Cortázar en la literatura en español va, evidentemente, mucho más allá de la creación léxica. A la ruptura en el plano literario (personajes difíciles de calificar, como los paredros, mezcla indiscriminada de puntos de vista y tiempos, estructura fragmentaria de la obra, combinación de materiales literarios y no literarios, etc.), le acompaña, como era de esperar, otra ruptura de tipo lingüístico, con una sintaxis entrecortada, arbitrariedades en la puntuación y en la ortografía, etc. Siendo, sin embargo, nuestro propósito eminentemente lexicológico, nos centraremos en esta sección final solo en aquellos aspectos relacionados más directamente con este propósito.

\footnotetext{
18 Fortran (contracción del inglés The IBM Mathematical Formula Translating System) es un lenguaje de programación desarrollado originalmente por IBM en los años cincuenta. Probablemente, Cortázar tuvo conocimiento de este lenguaje y se inspiró en él, pues ambos acrónimos ofrecen sorprendentes semejanzas: Formula Translating-Formulación transpuesta (agradecemos esta información a uno de los anónimos revisores de este trabajo).
} 
Los fenómenos relacionados con la puntuación y la tipografía constituyen un mecanismo sumamente efectivo en la literatura de vanguardia. Cortázar utiliza y reutiliza estos mecanismos de manera diversa y eficaz. Pero las convenciones ortográficas y tipográficas pueden ser fuente también de innovación léxica. Entre las más utilizadas por Cortázar (junto con muestras de escritura fonétic ${ }^{19}$ ), podemos señalar el empleo arbitrario de la $b$ (la bache fatídica, como es denominada en Rayuela ${ }^{20}$ ):

En esos días andaba caviloso, y la mala costumbre de rumiar largo cada cosa se le hacía cuesta arriba pero inevitable [...]. En esos casos Oliveira agarraba una hoja de papel y escribía las grandes palabras por las que iba resbalando su rumia. Escribía, por ejemplo: «El gran hasunto», o «la hencrucijada». Era suficiente para ponerse a reír y cebar otro mate con más ganas. "La hunidad», hescribía Holiveira. «El hego y el hotro.» Usaba las haches como otros la penicilina. Después volvía más despacio al asunto, se sentía mejor. "Lo himportante es no hinflarse», se decía Holiveira (R581).

También, y especialmente, los extranjerismos son sometidos a una manipulación consciente en el plano ortográfico, con el mismo fin de lograr complicidad, de distensión, de quitar hierro a situaciones aparentemente intrascendentes o absurdas detrás de las cuales

\footnotetext{
19 Muestras de escritura fonética se pueden rastrear en diferentes obras de Cortázar como en la cita del escritor y humorista argentino César Bruto que encabeza Rayuela. A este mismo principio responde la lengua ispamerikana utilizada en "Renovigo (Periódiko Rebolusionario Bilingue), publicación mexicana en lengua ispamerikana de la Editorial Lumen”, R453): “(Renovigo, $\mathrm{N}^{\circ}$ 5) / Otro suisida / Ingrata sorpresa fue leer en «Ortográfiko» la notisia de aber fayesido en San Luis Potosí el $1^{\circ}$ de marso último, el teniente koronel [...]” (R534). En realidad, todo el capítulo 69 de Rayuela está escrito en esta convención que Cortázar, a través de sus personajes, utiliza en más ocasiones en su obra.

20 "Intimidad, qué palabra, ahí nomás dan ganas de meterle la hache fatídica" (R555). Alguno de los autores importantes en la metaliteratura de Cortázar sirve de antecedente para este empleo expresivo de las convenciones ortográficas (Jacques Vaché, Alfred Jarry). Rayuela ("Del lado de allá”) comienza con una cita de Vaché, del que A. Amorós añade esta otra (1984: 117, n. 1): "Recuérdese su definición del humor, con la ortografía que recuerda a Jarry y anticipa algunos juegos de Cortázar: «l'umour, sens de l'inutilité théâtrale et sans joie de tout, quand on sait»”. La $h$, por su especial carácter, se presta para estos juegos bien por omisión o bien por adición.
} 
se esconde una profunda visión crítica de la literatura y de la realidad. Así el humorístico aeropiba (L985: base aeromoza) alterna con el anglicismo estiúvar (L983: steward) y con el galicismo otesdeler (L982: hôtesse de l'air). El recurso está omnipresente en su obra: ¿A vos no te parece, slípin biúti? (M243: ingl. Sleeping Beauty 'la bella durmiente'), nena comilfó (L1007: fr. comme il faut), bay que practicar sensaltro (L1077: it. senz'altro 'sin duda, por supuesto'), sin bablar del beséler (L1079: ingl. best seller), Desde el mejor sillón de la pieza Oscar asistía al jomsuitjom (L1095: ingl. home sweet home), las pomdeter van a brular (L1140: fr. brûler des pommes de terre), me contestaste con un sáidstep (L1184: ingl. sidestep), una vez más datoldblacmagicoldlov (L1184: that old black magic called love), etc.

Otros procedimientos tipográficos como la composición mediante guiones o la fusión ortográfica de frases serán analizados más abajo.

\subsection{Palabras posibles pero no existentes}

Hasta aquí nos hemos ocupado principalmente de innovaciones léxicas de carácter jitanjafórico, que más arriba hemos calificado como palabras posibles o potenciales. Con todo, cuando los morfólogos hablamos de palabras posibles pero no existentes no nos referimos a este tipo de palabras, sino más bien a aquellas otras motivadas morfológicamente en una lengua, es decir, palabras creadas de manera regular de acuerdo con las reglas de formación de palabras (RFP) que, por algún motivo, no existen en una lengua (fenómeno denominado bloqueo), pero podrían existir (o existen potencialmente); es decir, palabras formadas por derivación, composición, parasíntesis, entrecruzamiento, etc.

Estos procedimientos permiten incrementar de manera constante el léxico de una lengua con palabras adecuadas a nuevas realidades. A lo largo de estas páginas hemos mencionado reiteradamente la necesidad enunciada por Cortázar de destruir las viejas palabras para crear su antinovela. Las palabras viejas, manoseadas, ya no nos valen por lo que habremos de crear un léxico nuevo. Cortázar es maestro en esta técnica: Su experiencia como traductor, el constante 
manejo del diccionario, su actividad literaria desde adolescente, le permiten moverse con maestría en esa labor de crear un léxico nuevo allí donde de acuerdo con el tono de la obra le parece necesario.

De acuerdo con esta tarea, Cortázar en su renovación del lenguaje, en su ruptura con los moldes tradicionales, procede a una auténtica disección, análisis o desautomatización léxica. Para romper los moldes, antes deben analizarse con atención, observar sus principios, su funcionamiento. En este sentido, los juegos de descomposición léxica -deconstrucción- en busca de las múltiples asociaciones que se ocultan en el interior de una palabra son una característica que impregna a toda la literatura de vanguardia y, por tanto, también a Cortázar:

Nuestra verdad posible tiene que ser invención, es decir escritura, literatura, pintura, escultura, agricultura, piscicultura, todas las turas de este mundo. Los valores, turas, la santidad, una tura, la sociedad, una tura, el amor, pura tura, la belleza, tura de turas (R. 545).

Pureza. Horrible palabra. Puré, y después za. Date un poco cuenta (R208).

Si empezaba a tirar del ovillo iba a salir una hebra de lana, metros de lana, lanada, lanagnórisis, lanatúrner, lannapurna, lanatomía, lanata, lanatalidad, lanacionalidad, lanaturalidad, la lana hasta lanáusea pero nunca el ovillo (R567).

...asaltado como siempre después de una dura jornada por palabras sueltas que caían de la nada, desplegándose como los fosfenos contra los párpados del insomnio, la palabra trapisonda que daba trampa, sonda, trapa, pisos, trapos, el estrecho de Sonda, y con un leve cambio hasta un viento caliente que soplaba a veces en Mendoza y en la infancia ${ }^{21}$. Habituado a esas secuelas del trabajo, Juan se había parado en una esquina esperando lo que todavía pudiera brotar de la maleta trapisonda. Faltaba el pisón, pero vino antes de la honda, que fue la última chispa que alcanzó a dar la palabra al apagarse (M94).

21 Se refiere Cortázar al viento Zonda ("Arg. Viento fuerte, cálido, de extrema sequedad, proveniente de la precordillera cuyana, que afecta desfavorablemente a los seres vivos produciendo cierta inquietud y excitación”, DLE: s. v.). 
Era el deslinde, lo pensó quedándose en la palabra, dándole vueltas como a una fruta mental, deslinde, lindedés, delindes, lindesdé, ednilsed, sed de la linde, linde de la sed (L1091).

Anoche pensé en dar vuelta el asunto, desatar en vez de atar. Y en cuanto pensé en desatarlas vi la palabra al revés y daba sal, rata, sed. Cosas nuevas, fíjate, la sal y la sed (C1025).

Avanzando un poco más, esta descomposición léxica fruto de un análisis metalingüístico con frecuencia implica un verdadero análisis morfológico: el autor disecciona las palabras en sus componentes morfológicos y las reconstruye realizando diferentes combinaciones de morfemas a partir del radical o algún afijo, lo que constituye el fundamento metodológico de las creaciones morfológicas que abajo analizaremos (a partir de aquí la cursiva es nuestra en todas las citas):

Lo importante para Oliveira era [...] no incurrir en el pobre egocentrismo (criollicentrismo, suburcentrismo, cultucentrismo, folklocentrismo) que cotidianamente se proclamaba en torno a él bajo todas las formas posibles (R142).

...el jazz es como un pájaro que migra o emigra o inmigra o transmigra (R204).

Prescindiendo del diálogo rápidamente ascendido a tetrálogo, exálogo y dodecálogo, Oliveira cerró los ojos ${ }^{22}$ (R507).

...hay preludio, ludio y postludio (L1083).

\subsubsection{Derivación}

En castellano, el procedimiento más productivo para la creación de palabras nuevas es la derivación (Aguirre 2013: 59; Estornell 2009: 124). En alguna ocasión recurre Cortázar a la derivación impropia (es decir, sin afijo derivativo), con adición de los morfemas flexivos

\footnotetext{
22 En este caso, Cortázar procede a realizar un falso análisis ( $d i$-álogo $)$ de $d i$ - 'dos' en lugar del etimológico diá-logo, lo que le permite las reelaboraciones con otros prefijos de naturaleza numeral: tetra-, exa-, dodeca-, ('diálogo entre cuatro, entre seis, entre doce personas'). Curiosamente elude decálogo, la única palabra existente, por su significado estereotipado.
} 
directamente sobre la base, como sucede con el verbo despectivar 'mostrarse despectivo':

- Mirá -le dijo Oliveira [...] después de pelearse con Ronald que insistía en escuchar a Ma Rainey y se despectivaba contra Fats Waller (R189).

Con todo, como sucede en castellano (Pena 1991: 81), el principal procedimiento utilizado por Cortázar para la innovación léxica es la derivación mediante adición de afijos, especialmente sufijos.

En ocasiones, el propio Cortázar justifica la necesidad del neologismo porque su significado no se corresponde exactamente con la palabra tradicional formada sobre la misma base (deprimencial depresión) o porque designa una realidad anteriormente innombrable, carente de denominación (cosidad):

-Cómo no me voy a afligir - le contesto-. Me da una deprimencia, te juro.

- Usted quiere decir una depresión — pretende corregirme Lila.

- Nada de eso, m'hijita. La depresión es como algo que te va haciendo bajar y bajar, y al final quedas más aplastada que una raya, acordate de ese animal del acuario. En cambio la deprimencia te va subiendo todo alrededor, vos te debatís pero es inútil, y al final lo mismo quedas por el suelo como una hoja (M65).

- Usted ha repetido varias veces la palabra «cosa»—dijo Gregorovius-. No es elegante pero en cambio muestra muy bien lo que le pasa a Horacio. Una víctima de la cosidad, es evidente.

—¿Qué es la cosidad? —dijo la Maga.

- La cosidad es ese desagradable sentimiento de que allí donde termina nuestra presunción empieza nuestro castigo. [...] quiero decir que Oliveira es patológicamente sensible a la imposición de lo que lo rodea, del mundo en que se vive, de lo que le ha tocado en suerte (R199).

En algún caso, Cortázar prepara al lector —o juega con él—para que este sea consciente de la motivación de una innovación léxica. Obsérvese como en la siguiente cita el inexistente verbo afuerar ('hacer perder la concentración') se utiliza como antónimo de 
adentrarse, al que Cortázar marca preventivamente con un sic que nos permite estar alerta:

...a Marcos no se le podía ocurrir nada más brillante que subir los cinco pisos de mi dpto. justo cuando yo me adentraba (sic) en el noveno capítulo de una de esas novelas francesas de ahora en que todo el mundo es inteligentísimo, sobre todo el lector, motivo por el cual no me cayó demasiado bien que me afueraran con un timbrazo y qué tal Andrés, vengo a que me prestes el auto pero no hay apuro (L971).

En las lenguas naturales es frecuente la lexicalización (u opacidad léxica), fenómeno por el cual el significado real de una unidad, después de sufrir un proceso de desmotivación, no se corresponde con el previsto de acuerdo con las RFP. En estos casos, el autor puede crear una nueva voz que recupere el valor originario esperable, la cual llama la atención por el contraste. Es el caso de doblez, cuyo significado institucionalizado ('Astucia o malicia en la manera de obrar, dando a entender lo contrario de lo que se siente’, DLE: s. v.) permite a Cortázar crear una nueva palabra que recupere el valor predecible para la 'cualidad de lo doble', es decir, dobledad:

Soy doble, alguien que fue al cine y alguien que está metido en un lío típicamente cinematográfico. Pero esto de doble lo digo despierto, no había ninguna dobledad en el sueño, yo era yo y el de siempre (L960).

En líneas generales, las creaciones léxicas de Cortázar tienen una finalidad de juego, de humorismo, de ruptura con respecto a los moldes tradicionales o complicidad entre los personajes o entre autor y lectores, como sucedía con las construcciones jitanjafóricas. Pero con frecuencia, detrás de una escena cómica o más bien bufa o absurda - tan típicas en la producción cortaciana- se esconde una crítica profunda que el neologismo acentúa. De esta manera, el neologismo consciente refuerza el contenido del texto, al causar lo que los formalistas rusos denominaron extrañamiento, mediante el cual el autor intenta que el lector sea consciente de su auténtica realidad, pues la extrañeza aviva la percepción. La extrañeza, en estos 
casos, se consigue utilizando un léxico distinto del automatizado (el institucionalizado en el caudal tradicional) ${ }^{23}$ :

...ya ves, esos esquemas siguen fijos en gentes como nosotros, ya te das cuenta de que hablo de los pequeñoburgueses o de los obreros, la gente nucleada y familiada y casada y chimeneada y proleada (L994).

En definitiva, siempre que Cortázar utiliza un neologismo de su creación late detrás la imagen insospechada, el símil sorprendente (abelardizante 'castrador', wildear 'citar a Oscar Wilde', meandroso 'con circunloquios', penelopismo 'fidelidad femenina', wellingtoniano 'victorioso', champollionizar 'descifrar', bumeranguear 'lanzar como un bumerán', minifaldear 'llevar minifalda', mondrianizarse, etc.):

...resistencia que allá arriba se vuelve queja porque Diana o Jennifer sabe que ya no puede usar sus grandes tijeras sedosas abelardizantes en el plano mental y/o físico (L1013) ['no puede usar sus piernas como tijeras castradoras'. Abelardo fue castrado por su relación con Eloísa].

La naturaleza imita al arte, wildea Patricio (L1029).

A su manera más bien meandrosa el que te dije hubiera podido ayudar a Marcos a explicarle las hormigas a Ludmilla (L1101).

Comprendí que lo único que me quedaba era permitirle que se tirara en mis brazos como una ternera loca. Vos date cuenta qué abnegación, qué penelopismo exacerbado (R423).

...Heredia tumbaba su rey y asistía cejijunto a la sonrisa wellingtoniana de Gómez (L1154).

Los del Club [...] sostenían que era más fácil entender a Morelli por sus citas que por sus meandros personales. Wong insistió [...] que no valía la pena seguir molestándose en champollionizar las rosettas del viejo (R573).

Mondrian se conforma con que uno se mondrianice y se acabó (R165).

23 El término extrañamiento (ostranenie) fue creado por V. Shklovsky en 1916 en "El arte como artificio" (Crawford 1984). 
...las cosas me venían y yo las manipulaba y las revertía y las bumerangueaba sin salirme de mi cáscara (L893).

Abrir los ojos y ver [...] la silueta perfecta, minifaldeada y desodorada de Gladis (L985).

Entre los procedimientos derivativos preferidos por Cortázar destaca la afijación formada a partir de sufijos muy productivos como - dad (cosidad, alacranidad, tigredad, dobledad), -nte (yugulante, sudante, delegante, entregante), -ble (infaltable, jubilable):

...la llegada al chalet donde los trasbordos se cumplieron entre pinos fragantes, una especie de ruiseñor que cantaba en el bosque colindante, cosas solamente reservadas para el Vip jadeante y sudante (L1146).

...aunque toda la policía de París y los bomberos de La Plata corran [...] detrás de Gladis que le está tirando un puesto bien pagado y jubilable por la cara al capitán Pedernera (L1075).

Especialmente destacan los derivados adverbiales formados con el sufijo -mente (con chocantes desplazamientos semánticos: morenamente, pelirrojamente) y los adjetivos denominales construidos a partir de un nombre propio (especialmente de escritores, pensadores o artistas plásticos de los que se destaca, por antonomasia, una cualidad: mondrianesco, karamazófico, wellingtoniano, etc.):

Ronald se apoyó contra la puerta. Pelirrojamente en camisa a cuadros (R166).

El 56 acababa de morir esperadamente en el segundo piso (R470).

Otra cosa que lo preocupaba en esos días era un anuncio del New Statesman que microscópica y recuadradamente decía... (M43).

Pero pensar cazadoramente valía al menos como reingreso en este lado (M13).

... mi paredro, tirado ahora en el suelo y etruscamente apoyado en un codo (M202).

...y era malditamente cierto que yo iba por eso aunque no sólo por eso (L1198). 
... para meterme por las orejas unas sibilancias y unos bloques de materia sonora nunca escuchados sublunarmente hasta esta fecha (L885).

Apenas intente analizar meteré todo en la consabida fiambrera reticular y lo falsearé insanablemente (M11) ${ }^{24}$.

¡Un cosmos de colores puros, mondrianesco a reventar! (R700).

Espera la gran crisis karamazófica, el ataque celinesco (R339).

¿Qué colores eran esos, que ninguna marihuana michanxina o buxleyana traducía? (R699) ${ }^{25}$.

Ambos recursos (formaciones adverbiales sobre bases onomásticas) se combinan frecuentemente:

Sos dostoievskianamente asqueroso (R324).

Wittgensteinianamente, los problemas se eslabonan hacia atrás (R621).

Calac y Polanco compartían rioplatensemente una habitación del tamaño de un suspiro (M130).

Gómez lleva diez minutos protestando contra la música burguesa [...] defendiendo panameñamente un arte de participación multitudinaria (L956).

Heredia arquimédicamente sabrá que sólo necesita un punto de apoyo (L1014).

...todo lo cual contribuirá pestalozzianamente a amortiguar la compartimentación y el provincialismo de los pibes en cuestión (L1116) [Pestalozzi, pedagogo suizo, 1746-1827, muy influyente en Argentina (Castro 2016: 115)].

24 Dado que todas las palabras posibles, pero no existentes, tienen una presencia virtual en la lengua, puede darse el caso de que algún otro autor haya utilizado de manera independiente y también ocasional esa misma unidad. Es el caso de insanablemente: a pesar de no haber sido integrado en la norma del castellano, este adverbio fue usado por Alonso Fernández de Madrigal, El Tostado, en su Libro de las paradojas (1437), según podemos comprobar en el Corpus diacrónico del español (CORDE): "En los cuerpos de muchos dias muertos non se puede esto fazer por seer las arterias vocales insanablemente corruptas".

25 Michaux y Huxley hicieron ensayos de escritura bajo los efectos de las drogas (Amorós 1984: 699). 
Mucho menor uso hace Cortázar de la prefijación: acascarar 'crearse una cáscara de aislamiento' (L893), descomer (R164), [palomas] antigárgolas (R168), deseducación (R361), metapintura, metamúsica (R317), telepálpitos (R470), pericontar (L1106). Solo algún prefijo muy productivo como archi- (archipretérito, archisuficiencias, archicagados de miedo, archiclaro, archipodrida) ofrece un uso destacable:

Hacen falta otras potencias, otras opciones como dicen ahora, otras mediaciones como archidicen ahora (L871).

\subsubsection{Composición y parasíntesis}

Los mismos efectos logrados con la derivación se consiguen con la composición y otros procedimientos de formación de palabras de uso más limitado en castellano, como la parasíntesis, el entrecruzamiento, etc. Así, el compuesto posatigres, que da título a un cuento incluido en Historias de cronopios y famas (1962), designa una actividad de difícil interpretación. Algunos ejemplos de compuestos de distinta naturaleza y tono son amoricidio (R164), (color) borravino (R122), el mencionado aeropiba (sobre la base aeromoza 'azafata') (L983), antropofanía (R559), psicoespeleología (L907), (visión) pluriespectromutándica (L988) y otros como los siguientes:

...una visión multilenticular y en cuadricromía (L1101).

...el jazz es como un pájaro [...], saltabarreras, burlaaduanas (R204).

...hubo un interludio de cierraparaguas (R166).

...Bueno, Ronald tiene un vodka demasiado destrabalenguas (R270).

Mucho interés suscitan aquellos compuestos formados por la mera sucesión de palabras, a veces unidas por guion. Este simple procedimiento permite aumentar de manera considerable el léxico disponible formando una palabra de valor unitario en la que se integran en uno los significados de toda la combinación (con frecuencia el sintagma así unificado presenta de por sí un valor idiomático, con lo que solo se da carta de unión ortográfica a lo que ya está fijado en el uso: “correr como un reguero de pólvora”, “encogerse de hombros”, etc.): 
La noticia corriócomounreguerodepólvora (R602).

...lo miraba admirada y bebiendosuspalabrasdeunsolotrago (R616).

...los tres esperaron conteniendolarespiración (M206).

....anda a protestar en esa masaumanadelaseisimedia ['la gente en el metro en hora punta'] (L1198).

La Cuca y Ferraguto estaban-pendientes-de-sus-palabras (R459).

...condescendía a admitir que-para-ser-hembra-la-Maga-se-lastraí (R148).

En el fondo se quedaban un poco tristes pensando en posibilidades malogradas por el carácter argentino y el paso-implacable-deltiempo (R385).

...en cada caso se había referido a la inminencia de la gran tratativa y a las-pesadas-responsabilidades que caerían sobre todos ellos (suspiro) (R453).

Oliveira se-encogía-de-bombros (R459).

Cuca prestaba-un-oído-atento (R468).

Cuca se ha ido a dormir-un-sueño-reparador (R713).

...destinado a-sacarlo-de-sus-casillas (R497).

...hay-que-andarse-con-cuidado-en-esa-escena $(\mathrm{L} 1085)^{26}$.

Los procesos de composición y derivación son independientes, por lo que pueden combinarse de diferente manera (Pena 1991: 85). Las tres posibilidades se documentan en Cortázar, aunque de manera testimonial: composición con derivación interna (criptotransfusión, L962), derivación de un compuesto (recontramalparir, L1045), parasíntesis (quilombomorfismo L1145, librealbedrizar) ${ }^{27}$ :

No se trata de perfeccionar, de decantar, de rescatar, de escoger, de librealbedrizar, de ir del alfa hacia el omega (R674).

26 Los compuestos sintagmáticos unidos mediante guion no son desconocidos en castellano (físico-químico), pero Cortázar lleva este procedimiento a sus últimas consecuencias: “...complicaciones emotivo-mentales-físico-síquicas” (L911).

27 En la composición con derivación interna uno de los miembros que intervienen en la composición está previamente derivado ([cripto[transfus+ión]], según el modelo $[$ agua $[$ ardie $+n t e]])$, en la derivación de un compuesto el proceso es inverso ([re[contra] [mal+parir $]]$, según el modelo [[sordo+mud]ez]). En la parasíntesis ambos procesos son simultáneos ([libre+albedr+iza $(r)]$, [quilombo + morf $+i s m o]$, modelo [siete + mes + in $(o)])$. 


\subsubsection{Entrecruzamiento}

Relacionado con la composición está el entrecruzamiento (a veces denominado también acronimia ${ }^{28}$ ), este comparte con la composición el fundamentarse en la combinación de varias bases pero, a diferencia de esta, implica también un proceso de sustracción (normalmente el tipo de acrónimos prototípico está formado por el comienzo de una palabra y el final de otra, habiendo en medio algún fonema o sílaba común que sirve de nexo, pero las variaciones son grandes). Poco utilizado en la lengua común ${ }^{29}$, Cortázar aprecia sus posibilidades expresivas y, por ello, ofrece en su producción alguno de los ejemplos más logrados en castellano. En las páginas anteriores, hemos mencionado que muchas construcciones de base jitanjafórica utilizaban de manera heterodoxa este procedimiento, pero Cortázar, dentro de la variación que permite el recurso, también lo usa de una manera más convencional. En este sentido, se ha mencionado el término moteca, nombre con el que se denomina en el cuento "La noche boca arriba" (Final de juego 1956) la etnia del amerindio al que persiguen los aztecas durante la guerra florida. El acrónimo moteca, formado a partir de mot(ocicleta+az)teca, se adaptaría asombrosamente bien al otro entrecruzamiento que se produce en el cuento entre los sueños del protagonista.

Sin embargo, Cortázar ha rechazado reiteradamente esta explicación de moteca ${ }^{30}$. Sí nos hallamos ante un auténtico acrónimo

28 La peligrosa polisemia del término acronimia está recogida en el académico DLE (s. v. acrónimo):

1. m. Sigla cuya configuración permite su pronunciación como una palabra; p. ej., ovni: objeto volador no $i$ dentificado; TIC, tecnologías de la información y la comunicación.

2. m. Vocablo formado por la unión de elementos de dos o más palabras, constituido por el principio de la primera y el final de la última, p. ej., ofi(cina infor)mática, o, frecuentemente, por otras combinaciones, p. ej., so(und) n(avigation) a(nd) r(anging).

29 No es un procedimiento de formación de palabras natural en castellano, todas las formaciones de este tipo son creaciones individuales usuales en la prensa o literatura, con frecuencia anglicismos: motel [mot(or+bo)tel], metrosexual [metro(politan)+sexual], paralimpico [paral(itico+o)limpico], burkini [burk(a+bi)kini], Brangelina $[$ Bra $(d)+$ Angelina $]$, etc.

30 En Último round (I, 28) niega esta interpretación de "Roger Caillois que dedujo que los motecas, en La noche boca arriba, se llamaban así porque el protagonista del cuento andaba en moto". La misma refutación se repite en Cortázar (2009: 187). Otra justificación 
en el caso de explicontar (explicar+contar, L928), negacientífico (negación+científico, L899), mierdorrea 'verborrea continua de mentiras' (L1041), argudenuestos (argumentos+denuestos, L941), previboludecible previsible+boludo+decible (L1051), neumachirrianvirajes a ochenta (L1045) y en otros muchos casos como ${ }^{31}$ :

"la idea del pingüino turquesa me parece bastante antartiastuta" ('antártica' por el pingüino y 'astuta', L962).

...preguntándome si nos darían una pieza en el hotel Terrass, el problema de la no valija, de la parejobvia ('pareja obvia' por oposición a 'matrimonio', L1137).

\subsubsection{Permutaciones, palíndromos, anagramas}

Cortázar obtiene del entrecruzamiento todo el rendimiento funcional dando un paso más: su aplicación a unidades léxicas superiores a la palabra ${ }^{32}$, combinaciones en las que el entrecruzamiento conlleva la metátesis, el cambio en la secuenciación lineal de los componentes. Así, en el título de una conocida obra suya, Los autonautas de la cosmopista (1983), se produce bajo la apariencia de dos entrecruzamientos (auto[pista+cosmo]nauta, cosmo[nauta+auto] pista) la permutación de los respectivos constituyentes de ambas

del término podríamos hallarla en el náhutl: motecac. Ya aparece en el Vocabulario en lengua castellana y mexicana (Molina 1571, s. v.) con el significado 'acostado, tendido', cuya raíz teca significa 'extenderse, echarse' (Campbell 1985, s. v. teca: “мотесAC. MO-TECA-C. Lying down, or stretched out. Acostado, o tendido”). Pero, sin duda, Cortázar respondería a nuestra propuesta con la misma ironía dedicada a Roger Caillois.

31 En algunas ocasiones los acrónimos de tipo burlesco se acumulan. Así en Libro de Manuel (L1018), partiendo de la base hormiga (término utilizado por los protagonistas revolucionarios para referirse a la policía secreta enemiga), Cortázar nos ilustra con la siguiente retahíla de acrónimos hormigordos (hormiga+gordos), horminimos (bormiga+minimos), hormicrófonos (bormiga+micrófonos), hormicrocéfalos (bormiga+microcéfalo), formicológico (fórmico+farmacológico), al lado de compuestos y derivados como hormigóflos, hormigonudos, hormigócratas, hormigojetas, etc., que nos recuerdan series semejantes de V. Huidobro: "Ya viene viene la golondrina / Ya viene viene la golonfina / Ya viene la golontrina / Ya viene la goloncima / Viene la golonchina / Viene la golonclima / Ya viene la golonrima / Ya viene la golonrisa / La golonniña / La golongira / La golonlira / La golonbrisa / La golonchilla” (Altazor IV, 166-178).

32 Cual es el caso de unidades fraseológicas: Tienen piedra libre (L1087) (es decir, 'tienen la posiblidad de criticar/apedrear libremente' con base en la unidad fraseológica tener barra libre) o piloteando con su fangiofría (L1145) (Fangio+sangre fría). 
palabras. Lo mismo sucede en otro título como La vuelta al día en ochenta mundos (1967), en Aldey Huxdous (R208: Aldous Huxley) y en juegos alambicados como los siguientes ${ }^{33}$ :

...la medusa chupando solapada. La medusa solando chulapada (R354).

...en la punta de la mano... en la palma de la lengua (R209).

Te lo sagro por lo más jurado ('te lo juro por lo más sagrado' L899). ...esta noche a cada San Martín le llega su chancho (L1132).

Por otra parte, las modificaciones en el orden de los elementos constituyen uno de los fundamentos de las lenguas jergales. El lunfardo no es una excepción, pues acude con frecuencia al vesre, permutación del orden de las sílabas, en sus creaciones, de las que Cortázar es participante indirecto (gar-pa-r 'pagar': “...si sigue así vos podés ir garpando los mil francos”, M245). De índole personal son algunas creaciones basadas en una derivación de este tipo de metátesis: los anagramas. Con ellos intentaba la desequilibrada protagonista de uno de sus primeros cuentos ("Lejana. Diario de Alina Reyes") vencer las noches de insomnio: "Alina Reyes, es la reina y... Tan hermoso, éste, porque abre un camino, porque no concluye. Porque la reina y..." (Bestiario, C177). De esta naturaleza, es Pameos y meopas, título de un libro publicado en 1971, formado por la coordinación de dos anagramas de la palabra poemas. Junto con los anagramas, también los palíndromos son importantes en su producción (recordemos el nombre Calac de uno de los tártaros). En la colección Deshoras (1982), el cuento Satarsa se desarrolla a partir del palíndromo "atar a la rata" (Macías Rodríguez 2001), de cuyo plural ya no palindrómico surge Satarsa la rata, el antagonista que representa a la rata y a los militares que persiguen a los protagonistas:

- Pero si lo pensás en plural todo cambia. Atar a las ratas no es lo mismo que atar a la rata.

\footnotetext{
33 El mismo procedimiento se repite en varias ocasiones en Altazor: "Al horitaña de la montazonte / La violondrina y el goloncelo" (Canto IV, 162-163), "Empiece ya / La farandolina en la lejantaña de la montanía / El horimento bajo el firmazonte” (Canto V, 476-478).
} 
-No parece muy diferente.

—Porque ya no vale como palindroma — dice Lozano-. Nomás que ponerlo en plural y todo cambia, te nace una cosa nueva, ya no es el espejo o es un espejo diferente que te muestra algo que no conocías.

- ¿Qué tiene de nuevo?

- Tiene que atar a las ratas te da Satarsa la rata (Satarsa, C1025).

Otro palíndromo, Adán y raza, azar y nada, da comienzo a este cuento, cuyo protagonista, Lozano, obsesionado con los palíndromos y otros juegos de palabras, nos recuerda al niño Cortázar que jugaba escribiendo palabras en el aire seis décadas antes:

El hecho de ser un niño que al leer al revés una frase o una palabra encontraba una repetición o un sentido diferente -escribir en el aire «Roma» y luego leer «amor» al invertirla- me resultaba fascinante. Cuando descubrí los palíndromas ([...] en un libro encontré el primero, el clásico, ese que dice «Dábale arroz a la zorra el abad», que es una frase muy larga) cuando la escribí en el papel o en el aire y me di cuenta de que decía la misma cosa, me sentí instalado en una situación de relación mágica con el idioma (Prego 2015: 26).

\section{Conclusiones}

En las páginas anteriores hemos intentado demostrar la importancia que Julio Cortázar concedió a la creación de neologismos dentro de su proyecto personal de renovación del lenguaje literario.

Así, hemos observado como este autor concede tanta importancia a los procedimientos regulares con que cuenta una lengua en este proceso de creación (reglas de formación de palabras: generales como la derivación o la composición; ocasionales como son los entrecruzamientos, los anagramas o palíndromos) como a aquellos otros casi exclusivos de la producción literaria (diferentes tipos de creaciones jitanjafóricas).

Estos procedimientos están complementados con otros marginales como la manipulación ortográfica (especialmente en extranjerismos) y tipográfica. 
En estos juegos léxicos, que buscan la colaboración del lector activo, está con frecuencia latente la parodia o sátira contra el lenguaje ampuloso y el léxico escogido de la literatura esteticista que intenta superar.

\section{Referencias bibliográficas}

Aguirre, Carmen

2013 Manual de Morfología. Barcelona: Castalia.

Alemany y Bolufer, José

1920 Tratado de formación de las palabras de la lengua castellana. Madrid: Librería general de Victoriano Suárez.

Amorós, Andrés

[1963] 1984 “Introducción”. En Rayuela. Cortázar. Madrid: Cátedra, 15-92.

CAmpbell, R. Joe

1985 A morphological dictionary of classical Nabuatl. Madison: Hispanic Seminary of Medieval Studies.

CAmpos López, Ronald

2017 “Neologismos en la poesía de Laureano Albán”. Onomázein. 36, 183-197. https://doi.org/10.7764/onomazein.36.10

Casado Velarde, Manuel

2015 La innovación léxica en el español actual. Madrid: Síntesis.

Castro, Juan C.

2016 Idiomas espectrales. Lenguas imaginarias en la literatura latinoamericana. Bogotá: Editorial Pontificia Universidad Javierana. https://doi.org/10.2307/j.ctv893gk4

CORDE $=$ REAL ACADEMIA ESPAÑOLA

$\mathrm{s} / \mathrm{f} \quad$ Corpus diacrónico del español (CORDE). Consultado: $12 \mathrm{de}$ julio de 2017. <http://corpus.rae.es/cordenet.html>.

CORTÁzAR, Julio

[1963] 1984 Rayuela. Ed., Andrés Amorós. Madrid: Cátedra.

[1968] 1979 62. Modelo para armar. Buenos Aires: Editorial Sudamericana.

[1969] 2004 Último round. México: Siglo XXI de editores. 
[1973] 2004 Libro de Manuel. En Novelas II. Ed., Saúl Yurkievich con la colaboración de Gladis Anchieri. Barcelona: Galaxia Gutemberg-Círculo de Lectores.

2003 Cuentos completos. Ed., Saúl Yurkievich con la colaboración de Gladis Anchieri. Barcelona: Galaxia Gutemberg-Círculo de Lectores.

2006 Obra crítica. Ed., Saúl Yurkievich con la colaboración de Gladis Anchieri. Barcelona: Galaxia Gutemberg-Círculo de Lectores.

2009 Papeles inesperados. Eds., Aurora Bernárdez y Carles Álvarez Garriga. Madrid: Alfaguara.

Cortázar, Julio y Carol Dunlop

1983 Los autonautas de la cosmopista. O un viaje atemporal París Marsella. Barcelona: Muchnik.

Crawford, Lawrence

1984 "Viktor Shklovskij: Différance in Defamiliarization". Comparative Literature. 36, 209-219.

De Molina, Alonso

1571 Vocabulario en lengua castellana y mexicana. México: Antonio de Spinosa. Consultado: 6 de junio de 2017. <https://archive. org/stream/vocabularioenlen00moli\#page/n3/mode/2up>

DLE $=$ REAL ACADEMIA ESPAÑOLA

2014 Diccionario de la lengua española (DLE). Madrid: Espasa.

Eguren GutiérRez, Luis J.

1987 Aspectos lúdicos del lenguaje. La jitanjáfora, problema lingüístico. Valladolid: Universidad.

Estornell Pons, María

2009 Neologismos en la prensa. Valencia: Universidad de Valencia. García Ávila, Aldo

2013 “"Donde tu hermosura se ensombra»: problemas morfosemánticos en el 'Comentario VII', de Juan Gelman”. Acta poética. 34, 214-236. https://doi.org/10.19130/iifl.ap.2013.2.426

García-Page, Mario

2009 "Notas sobre la creatividad léxica. Acrónimos, seudoacrónimos y otras extravagancias léxicas en la poesía de Gloria Fuertes”. En Lengua viva. Estudios ofrecidos a César Her- 
nández Alonso. Eds., Antonio Álvarez, Antonio Bueno, Silvia Hurtado y Nieves Mendizábal. Valladolid: Universidad de Valladolid, 363-372.

2012 "La derivación verbal en César Vallejo". «Assí como es de suso dicho». En Estudios de morfología y léxico en homenaje a Jesús Pena. Eds., Mar Campos, Ramón Mariño, J. Ignacio Pérez Pascual y Antonio Rifón. San Millán de la Cogolla: Cilengua, 243-257.

González Calvo, José M.

1981 "La creación neológica en la poesía de Juan Ramón Jiménez". En Juan Ramón Jiménez en su Centenario. Cáceres: D. P. del Ministerio de Cultura, 27-51.

2003 "Los neologismos en la literatura durante el primer tercio del siglo XX”. En El lenguaje de la literatura (1898-1936.). Coords. Ricardo Senabre, Ascensión Rivas e Iñaki Gabaráin: Salamanca: Colegio de España-Ambos Mundos, 85-104.

GonzÁlez Dueñas, Daniel

2013 “Dos juegos centrales”. Revista de la Universidad de México. 114, 40-48.

Heredia, Pablo

2014 "Literatura y política: el lenguaje del neologismo en Juan Gelman”. En V Congreso Internacional de Letras. Eds., Américo Cristófalo y Jerónimo Ledesma. Buenos Aires: Editorial de la Facultad de Filosofía y Letras, 1579-1583.

Herrero, José L.

2001 "Cultismos, americanismos y neologismos en la poesía de Mario Benedetti”. En Estudios sobre el español de América. Eds., Hermógenes Perdiguero y Antonio Álvarez. Burgos: Universidad de Burgos, 776-792.

Huidobro, Vicente

[1931] 1981 Altazor. Ed., René de Costa. Madrid: Cátedra.

Lagmanovich, David

1997 "Los 'lenguajes inventados' como recurso literario”. En Lectura crítica de la literatura bispanoamericana. Actualidades fundacionales. Ed., Saúl Sosnowski. Caracas: Biblioteca Ayacucho, 263-278. 
LÓpez MarTínez, María I.

1992 “Neologismos en la poesía de Vicente Aleixandre”. En Actas del II Congreso Internacional de Historia de la Lengua española. Vol. 2. Coord. Manuel Ariza Viguera. Madrid: Pabellón de España, 691-702.

Macías Rodríguez, Claudia

2001 "El alcance del juego de las palabras en Satarsa, de Julio Cortázar”. Sincronía. 19. Consultado: 6 de junio de 2017.

$<$ http://sincronia.cucsh.udg.mx/satarsa.htm>.

MaÑu Iragui, Jesús

1974 Estructuralismo en cuatro tiempos: ensayos críticos sobre Dario, Cortázar, Fuentes y García Márquez. Caracas: Equinoccio.

Marchamalo, Jesús

2011 Cortázar y los libros: un paseo por la biblioteca del autor de "Rayuela". Madrid: Fórcola.

Martín Camacho, José C.

1994 "Consideraciones sobre la creatividad léxica: El ejemplo de Juan Goytisolo". Anuario de Estudios Filológicos. 17, 307-324.

1995 "Consideraciones sobre la creatividad léxica: El ejemplo de Juan Goytisolo (y 2)”. Anuario de Estudios Filológicos. 18, 275-292.

Meo Zilio, Giovanni

1968 "Neologismos en la poesía de César Vallejo". En Actas del XI Congreso Internacional de Lingüistica y Filología Románicas. Vol. 2. Coords. Antonio Quilis, Ramón B. Carril y Margarita Cantarero. Madrid: Revista de Filología Española, 951-966.

Morales Benito, Lidia

2014 "Alfred Jarry: la lengua como artilugio lúdico para nuevas interpretaciones. Metamorfosis de las palabras”. Quimera. Revista de Literatura. 367, 24-29.

OrOz, Rodolfo

1967 "Sobre neologismos en la poesía de Gabriela Mistral”. Boletín de la Academia Chilena. 55, 29-54.

Pena, Jesús

1991 “La palabra: estructura y procesos morfológicos”. Verba. 18, 69-128.

1999 "Partes de la morfología. Las unidades del análisis morfológico”. En Gramática Descriptiva de la Lengua Española. Vol 
3. Dirs. Ignacio Bosque y Violeta Demonte. Madrid: Real Academia Española-Espasa Calpe, 4305-4366.

Pradenas, Luis

2006 Teatro en Chile. Huellas y trayectorias. Siglos XVI-XX. Santiago de Chile: LOM Ediciones.

Prego, Omar

1985 La fascinación de las palabras. Conversaciones con Julio Cortázar. Barcelona: Muchnik.

Pulido Mendoza, Manuel

2001 "Creación léxica y estética posmoderna en la obra literaria de Manuel Pacheco". Revista de estudios extremeños. 57, 421-438.

Real Academia Española

1950 Diccionario Manual e ilustrado de la Lengua Española. Madrid: Espasa-Calpe.

RodrígueZ FERrÁndiz, Raúl

1997 "El anagrama saussuriano. Los textos y la crítica”. Signa. 6, 385-414.

Romero Gualda, María V.

1980 "Hacia una tipología del neologismo literario". Anales de la Universidad de Murcia. 37, 145-154.

Serrano Dolader, David

1997 "Reflexión sobre el lenguaje y creación léxica en las novelas de Francisco Nieva”. Iberorromania. 46, 20-39.

2012 "Noventa años de descripción de la morfología léxica española: tratados de formación de palabras en español (1920-2010)". En La sabiduría de Mnemósine. Ensayos de Historia de la Lingüistica ofrecidos a José Francisco Val Álvaro. Eds., José Luis Mendívil Giró y M. ${ }^{a}$ del Carmen Horno Chéliz. Zaragoza: Prensas Universitarias de Zaragoza, 113-127.

Soldevila Durante, Ignacio

1990 "La creatividad léxica de Camilo José Cela". Hispanística XX. $8,103-118$.

Vallejo, César

[1922] 1991 Trilce. Ed., Julio Ortega. Madrid: Cátedra. 